\title{
Propaganda ditatorial e invasão do cotidiano: a ditadura militar em perspectiva comparada*
}

\author{
Dictatorial propaganda and the invasion of everyday life: the military regime in Brazil \\ in comparative perspective
Propaganda dictatorial e invasión del cotidiano: la dictadura militar brasileña en perspectiva comparada

\begin{abstract}
Nina Schneider**
Resumo: As ditaduras do século XX usaram máquinas de propaganda distintas para justificar o seu poder ilegal. Durante o nazismo e o stalinismo, por exemplo, foram montados grandes sistemas de propaganda, envolvidos tanto na produção quanto na censura de conteúdo, que, em conjunto com outras medidas políticas (repressão violenta, vigilância, organizações de participação obrigatória, etc.), visaram a mobilizar as massas em favor do regime e silenciar qualquer tipo de oposição política. Durante o Estado Novo (1937-45), também foi montado um aparato amplo no Brasil, que tentou reforçar a sensação da união entre o suposto líder, Getúlio Vargas, e o povo (mais especificamente o trabalhador urbano) - o chamado Departamento de Imprensa e Propaganda (DIP). Tomando como foco de análise a ditadura militar brasileira (1964-1985) e oferecendo uma primeira aproximação, esta contribuição investiga como a propaganda oficial - ou o órgão responsável pelas campanhas oficiais - influenciou a vida cotidiana dos cidadãos brasileiros e até que ponto o regime tentou invadir a vida privada. Revisando a pesquisa atual, este artigo pergunta: quem foi influenciado e por quais meios? O que sabemos sobre o efeito das campanhas? É possível perceber que, muito diferentemente da ditadura nazista e varguista, o regime militar operou um órgão de propaganda oficial pequeno, que rejeitou uma estratégia de politizar e mobilizar o cidadão brasileiro, bem como de invadir a sua vida cotidiana de maneira tão agressiva. Pelo contrário: apoiou-se a iniciativa privada e o livre-mercado como pilares fundamentais do sistema capitalista. Com a contratação de produtores do mercado cinematográfico, campanhas oficiais com um caráter desmobilizador e aparentemente apolítico foram elaboradas.
\end{abstract}

Palavras-chave: Propaganda oficial; O cotidiano; Ditadura; Regime militar brasileiro; AERP; Consentimento; Propaganda nazista; DIP.

\begin{abstract}
The dictatorships of the twentieth century used different kinds of propaganda machines to justify their illegal rule. During the Nazi dictatorship and under Stalinism, for example, huge propaganda organs were created that both produced propaganda and became engaged in censorship. Combined with further political mechanisms (violent repression, surveillance, obligatory organisations, etc.), these means were used in order to mobilise the masses in favour of the regime and to silence any form of political dissent. During the New State (1937-45) a similar propaganda apparatus was built in Brazil that tried to amplify the notion of a union between the supposed leader figure, Getúlio Vargas, and the people (more specifically the urban working class). This propaganda organ - the so-called Departamento de Imprensa e Propaganda (DIP) - tried to annihilate the difference between the public and the private sphere. Focusing on the Brazilian military dictatorship (1964-1985) and offering a preliminary analysis, this article investigates to what extent Brazilian citizens were subjugated to the influence of official propaganda in their everyday lives, and to what extent the regime invaded their private lives. Drawing on the state of art, the
\end{abstract}

\footnotetext{
* Apoio do Global South Study Center (GSSC) da Universidade de Colônia.

** Pesquisadora Sênior do Centro de Estudos Sobre o Sul Global (Global South Study Center, GSSC) da Universidade de Colônia, Alemanha e Pesquisadora Associada do Zukunftskolleg, Universidade de Constança, Alemanha. Doutora em História na University of Essex, Grã-Bretanha.
} 
article asks: Who was influenced and by which means? What knowledge do we have about the effect of the campaigns? The article shows that in contrast to the Nazi and Vargas dictatorships, the military regime operated only a small propaganda organ that rejected a politicisation and mobilisation of Brazilian citizens and refused to invade their everyday lives in an aggressive manner. To the contrary, the regime supported the private initiative and free-market ideology as one of capitalism's building blocks; hired civilian filmmakers to produce their propaganda; and opted for depoliticising and supposedly apolitical campaigns. Keywords: Official propaganda; Everyday life; Dictatorship; The military regime in Brazil; AERP; Collaboration; Nazi propaganda; DIP.

Resumen: Las dictaduras del siglo XX usaron máquinas de propaganda distintas para justificar su poder ilegal. Durante el nazismo y estalinismo, por ejemplo, fueron montados grandes sistemas de propaganda, responsables tanto para la producción cuanto la censura de contenido. Junto con otras medidas políticas (represión, violenta, vigilancia, organizaciones obligatorias, etc.), estas prácticas visaron movilizar las masas en favor del régimen y silenciar cualquier tipo de oposición política. Durante el Estado Nuevo (1937-45) también fue montado un aparato amplio en el Brasil, que intentó reforzar la sensación de una unión entre el supuesto líder, Getúlio Vargas, y la población (más específicamente el trabajador urbano), y aniquilar la distinción entre la vida pública e privada - el Departamento de Prensa y Propaganda (DIP). Tomando como foco del análisis la dictadura militar brasileña (1964-1985) y ofreciendo una primera aproximación, esta contribución investiga hasta cómo el ciudadano brasileño fue sometido a la influencia de la propaganda oficial en su vida cotidiana, y hasta qué punto el régimen invadió su vida privada. Resumiendo el estado de investigación actual sobre el tema, pregunta: ¿Quién fue influenciado y por cuáles medios? ¿Y qué sabemos sobre el efecto de las campañas? El artículo muestra que muy diferentemente de la dictadura nazista y varguista, el régimen militar operó un órgano de propaganda oficial pequeño, que rechazó la politización y movilización estratégica del ciudadano brasileño y de invadir su vida cotidiana de una manera agresiva. Al contrario, se apoyó la iniciativa privada, el libremercado como pilares fundamentales del sistema capitalista; se contrató productores de propaganda del mercado de cine; y se producía campañas oficiales con carácter desmovilizador y aparentemente apolítico.

Palabras clave: Propaganda oficial; Cotidiano; Dictadura; Régimen militar brasileño; AERP; Consentimiento; Propaganda nazista; DIP.

As ditaduras do século XX usaram máquinas de propaganda distintas para justificar o seu poder ilegal. Durante o nazismo e o stalinismo, por exemplo, foram montados grandes sistemas de propaganda, envolvidos tanto na produção quanto na censura de conteúdo, que, em conjunto com outras medidas políticas (repressão violenta, vigilância, organizações de participação obrigatória, etc.), visaram a mobilizar as massas em favor do regime e silenciar qualquer tipo de oposição política. Durante o Estado Novo (1937-45), também foi montado um aparato amplo no Brasil, que tentou reforçar a sensação da união entre o suposto líder, Getúlio Vargas, e o povo (mais especificamente o trabalhador urbano) - o chamado Departamento de Imprensa e Propaganda (DIP).

Tomando como foco de análise a ditadura militar brasileira (1964-1985) e oferecendo uma primeira aproximação, esta contribuição investiga como a propaganda oficial influenciou a vida cotidiana dos cidadãos brasileiros, e até que ponto o regime tentou invadir a vida privada. Revisando o estado da pesquisa atual sobre o tema, a presente publicação pergunta: quem foi influenciado e por quais meios? $\mathrm{O}$ que sabemos sobre o efeito das campanhas? $\mathrm{O}$ artigo mostra que, muito diferentemente da ditadura nazista e varguista, o regime militar operou um órgão de propaganda oficial pequeno, que rejeitou uma estratégia de politizar e mobilizar o cidadão brasileiro, bem como de invadir a sua vida cotidiana de maneira tão agressiva ${ }^{1}$. Pelo contrário, apoiou-se a iniciativa privada e o livre-mercado como pilares fundamentais do sistema capitalista. Contratou-se produtores do mercado de cinema e produziu-se campanhas oficiais com um caráter desmobilizador e aparentemente apolítico. Em relação ao conteúdo, fingiu-se que o Brasil estava vivendo uma época de harmonia, sem conflitos sociais nem preocupações.

\footnotetext{
1 Enquanto alguns historiadores priorizam o termo regime civilmilitar, o termo mais comum hoje, prefiro usar o termo regime militar para enfatizar que o poder de governar o país strictu sensu esteve nas mãos dos militares, o que ficou claramente visível depois de 1968; uma postura semelhante àquela de Marcos Napolitano (NAPOLITANO, 2014, p. 347). Reconheço a importância da intervenção "revisionista" principalmente por parte de historiadores da Universidade Federal Fluminense (UFF) e da Universidade de Campinas (UNICAMP) de colocar a questão do apoio civil na agenda tanto da pesquisa quanto da memória social. Como argumentam, por exemplo, Daniel Aarão Reis Filho (2000), Janaina Martins Cordeiro (2015) e Marcelo Ridenti (2016), este apoio incômodo ainda esta sendo negado na memória social, que, de grosso modo, prefere culpar somente os militares ou enfatizar a "resistência" da oposição política. Quero deixar bem claro que, ao adotar o termo regime militar não pretendo de forma alguma negar o apoio civil maciço em distintas áreas e distintas fases da ditadura militar, especialmente em 1964, no momento do golpe civil-militar, e na época do chamado "Milagre" (1968-1973). Concordo com Ridenti (2016) no fato de que a questão importante não é a designação, mas o reconhecimento e estudo detalhado do apoio civil. Esse artigo tenta fazer uma contribuição a tal projeto.
} 
Embora o regime ilegal tenha sido justificado pelos mais diversos meios, é importante diferenciá-los. Este artigo concentra-se no papel dos órgãos estatais instituídos pelas ditaduras para produzir campanhas propagandísticas, bem como no alcance desses sobre o cotidiano do "cidadão comum" (não ativamente engajado na oposição ao regime). Os cidadãos foram submetidos a outros mecanismos de propaganda próregime, dentre eles a mídia privada, que veiculava propaganda do tipo chapa-branca, e as matérias obrigatórias nas escolas e universidades, como Educação Moral e Cívica (EMC), implementadas pelo Ministério de Educação e Cultura (MEC), e não pelos órgãos oficiais de propaganda. Devido à sua amplitude, esses outros instrumentos, que também impactaram na vida cotidiana do brasileiro comum, não poderão ser abordados aqui (para isso, veja SCHNEIDER, 2014, p. 65-84).

Do ponto de vista teórico, durante muito tempo, estudiosos nutriram uma imagem de uma propaganda todo-poderosa (ou, em inglês, a teoria magic bullet). Pensava-se, e Siegfried Kracauer (1947) foi um dos seus principais articuladores, que a propaganda, uma vez estreada na mídia de massa, iria automaticamente, manipular o sujeito de recepção (ou seja: a audiência iria acreditar no que escutava e via nos meios de comunicação sem nenhum senso critico próprio) (GUREVITCH, BENNETT, CURRAN e WOLLACOTT, 1992, p. 11, DEFLEUR e BALLROKEACH, 1989, p. 163-166). De forma semelhante, pensadores icônicos da Escola de Frankfurt, como Adorno e Horkheimer, têm uma visão opressora da cultura de massa. Fundada em 1923 na Alemanha por um grupo de intelectuais de várias disciplinas, a Escola de Frankfurt desempenhou um papel importante em colocar o estudo da mídia de massa em pauta. Contrapondo-se ao determinismo materialista, esse grupo marxista heterogêneo reconheceu a cultura como fator importante para a sociedade. Por consequência, muitos estudavam de que maneira produtos culturais como o cinema, a fotografia ou a música eram "portadores de ideologia" (ideological carriers), os quais sustentavam o capitalismo (WALKER, 2015). Adorno e Horkheimer (1972) atacaram a mídia de massa como um novo e nefasto meio para controlar a população. Benjamin (1969), pelo contrário, tinha uma opinião mais ambivalente em relação à mídia de massa e à reprodução mecânica. Embora Benjamin, que era ligeiramente ligado à Escola de Frankfurt, criticasse a perda da aura artística devido à reprodução mecânica da tecnologia fotográfica, ele também reconhecia seu efeito democratizante (a reprodução artística para as massas), oferecendo uma avaliação tanto negativa como positiva. Uma das críticas mais ferrenhas contra a visão determinista de Adorno e Horkheimer, é precisamente a de que essa teoria nega a habilidade do indivíduo de resistir à cultura industrial (WALKER, 2015).

Essa imagem de uma propaganda todo-poderosa ainda é perpetuada em muitos estudos. É, no entanto, sobretudo na memória social que ela se reflete. Maria Helena Weber (2000, p. 180), por exemplo, alega no seu livro sobre a propaganda da ditadura militar brasileira: "A rede repressiva atuava diretamente sobre a produção simbólica, sobre o pensamento e sobre as ações dos cidadãos". Esse tipo de visão estereotipada da propaganda também foi criticada pelo historiador Carlos Fico (1997, p. 16-20) na sua obra clássica sobre a propaganda do regime militar. Ele refuta perspectivas que reduzem a propaganda à ideologia ou a classes sociais, e prefere uma análise que esteja enraizada no contexto econômico-social e que considere os anseios da população em relação ao futuro (por isso, ele opta pelo conceito do imaginário social). As pesquisas neomarxistas mais recentes, associadas à escola de Stuart Hall em Birmingham, sugerem uma análise da comunicação de massa no sentido de uma dialética complexa entre a mídia, a comunicação e o poder social. Diferenciando ser social de consciência social (FEJES, 1984, p. 219-20), essa escola supera uma noção simplificadora da "consciência de classe" e enfatiza o papel do contexto social no qual mensagens midiáticas são produzidas e recebidas.

Até mesmo no que se refere à propaganda nazista, ainda carecemos tanto de pesquisas empíricas sobre o efeito da propaganda na opinião pública e os seus limites quanto sobre os métodos de pesquisa da recepção de tais campanhas (HILDEBRAND, 2003, p. 244; ZIMMERMANN, 2007, p. 25-29). Sobre esse caso peculiar de um sistema de propaganda massivo, acompanhado por violência sistemática desde 1929 (anterior à ascensão de Hilter em 1933; WILDT, 2008, p. 54), o estudo pioneiro de um de seus maiores especialistas, Ian Kershaw (1980, p. 10-12, 16, 130), revela: o mito de Hitler não foi somente o sucesso das campanhas de propaganda, mas também fruto da capacidade de responder aos principais anseios e desejos da população. Kershaw (1980, p. 12, 149-191) chama o estudo desses anseios, desejos e expectativas da população de "imagologia", e demonstra em seu livro como a maioria do povo alemão co-construiu o mito de Hitler. Somente após 1942, quando os alemães começam a perder a guerra e a sofrer cada vez mais com 
os ataques de bombas e a fome, que eles lentamente passam a perceber que o Hitler real era distinto do Hitler que eles tinham imaginado. Porém, como bem salienta Kershaw, esse foi um processo muito longo, difícil de ser compreendido e aceito.

Tanto pesquisas sobre comunicação política quanto exemplos empíricos têm questionado esse pressuposto (ou talvez estereótipo) da propaganda todo-poderosa. De fato, entretanto, é sabido que a propaganda pode ter pouca influência ou até mesmo o efeito oposto - nutrir dúvidas e receios frente a governos ou novas ideias. Um exemplo da propaganda nazista são os filmes de longametragem explicitamente antissemitas, que não fizeram tanto sucesso, e que obrigaram os propagandistas a produzir outros tipos de filmes (ZIMMERMANN, 2007, p. 165; ALBRECHT, 1969). Um exemplo brasileiro é o famoso programa radiofônico $A \mathrm{Voz} d o$ Brasil, que não era ouvido pela maioria dos cidadãos brasileiros. ${ }^{2}$ Carecemos de métodos e teorias para julgar o efeito exato da propaganda. O trabalho dos pesquisadores das últimas décadas, de um modo geral, tem sido o de desenvolver um catálogo cada vez mais nuançado de fatores que influenciam a recepção, e de elaborar métodos para estudar as complexas interrelações entre comunicação de massa, ideologia e relações sociais de poder (inclusive de classe).

Sabemos, hoje, que cada caso de recepção da propaganda tem que ser estudado empiricamente, e que qualquer teoria, que pressupõe de antemão uma relação direta, e automática entre a propaganda e o "sujeito manipulado", é uma simplificação pouca iluminadora. Haja vista a contribuição de historiadores, que aplicam métodos de análise crítica de fontes. Considero que muitos outros fatores, além da propaganda oficial, podem contribuir para a formação de opiniões sobre ditaduras e a forma de consentimento com o regime (HALL, 1992). Contudo, neste artigo, vou focar especificamente no aspecto da exposição à propaganda e mapear o nosso conhecimento sobre a recepção da propaganda militar, com base em fontes empíricas. A pergunta muito mais ampla, sobre quais formas de consentimento essa propaganda causou, mereceria um livro inteiro. Mesmo rejeitando teorias maniqueístas de propaganda, podemos sim estudar empiricamente como as ditaduras do século XX usaram máquinas de propaganda historicamente específicas (com dimensões, estratégias e métodos distintos). Podemos analisar se elas visaram a mobilizar a população inteira,

2 Ethevaldo Siqueira (2000, p. 147) ridiculariza o programa com a seguinte brincadeira: "Avós do Brasil? Não! A voz do Brasil". aniquilando a diferença entre o público e o privado, e se a propaganda oficial teve maior ou menor alcance e presença na vida cotidiana dos cidadãos.

Nas últimas décadas, a prática de uma História Comparada foi muito criticada. Alegou-se que a seleção de casos e conceitos é arbitrária, e que o método comparativo pouco considera a mudança e a adaptação dos fenômenos estudados com o passar do tempo (KAELBLE, 2005). Em 1994, Michel Espagne sugeriu o conceito do transfert culturel, e logo após foram testados novos métodos para relacionar e contrastar casos históricos distintos como, por exemplo, a entangled history de Shalini Randeria e Sebastian Conrad (2002) ou o livro De la comparaison à l'histoire croisée de Michael Werner e Benedicte Zimmermann (2004). Como bem comenta Kaelble (2005, p. 5), tal transformação metodológica também reflete o processo histórico-social, como a substituição do papel do Estado-nação pela transnacionalização. Ainda assim, como lembra Fulbrook (2002, p. 116-118), a prática de uma História Comparada pode servir para analisar um certo fenômeno que acontece em vários contextos geográficos ( $\mathrm{p}$. e. o Renascimento na Itália e na Dinamarca). Ou seja, serve para estabelecer padrões gerais que marcam vários contextos específicos, ou mesmo para identificar as especificidades de um certo contexto. Fulbrook também salienta que embora vivamos numa época de "História anticomparada", muitas vezes a comparação está implícita na análise, mesmo no caso extremo do Holocausto, que, na visão de muitos críticos, é único e jamais poderá ser comparado. É neste sentido que esta contribuição visa a contrastar a propaganda ditatorial e a invasão do cotidiano: para estabelecer o que foi único no regime militar brasileiro frente a outras ditaduras do século XX.

Consciente do perigo de comparar sistemas de propaganda de contextos históricos muito distintos e marcados por relações e dinâmicas político-sociais peculiares (ainda mais num artigo tão pequeno como este), eu gostaria de contrapor sistemas de propaganda ditatoriais com o objetivo de definir o grau de influência da propaganda oficial brasileira na vida cotidiana do final dos anos 1960 e 1970 . Quando se desconhece outros sistemas de propaganda, surge o risco de superestimar e simplificar tanto a dimensão institucional quanto o alcance das campanhas oficiais, bem como de desconsiderar a relação específica entre o estado e as instituições privadas. De fato, o interesse de um regime ditatorial em invadir o espaço privado do cidadão comum e em controlar o cotidiano, influencia, fundamentalmente, a natureza peculiar do consentimento civil em cada ditadura. 
Comecemos pelo caso alemão. Os nazistas controlaram as mídias de massa não somente por meio da censura e da repressão violenta, mas também ao ditar conteúdos a serem publicados pelos editores de jornais em conferências de imprensa diárias em Berlim (ZIMMERMANN, 2007, p. 85-88, 129-134). ${ }^{3}$ Dentre muitos outros mecanismos de controle, havia o registro profissional obrigatório para cada jornalista ou artista na chamada Reichskulturkammer, coagindo-os a retirar uma licença para exercer a sua profissão (HILDEBRAND, 2003, p. 245). Em termos de conteúdo, aqui menos tratado, destacam-se a ideologia racista dos nazistas (inclusive a fetichização do chamado Arier e o antissemitismo ferrenho), o culto pessoal de Hitler, encenado como salvação do povo alemão, e a propaganda agressiva contra o comunismo. Além da imprensa, um dos principais veículos dessa ideologia era o rádio. Também foram implementadas as famosas notícias obrigatórias nos cinemas (os Wochenschauen), que antecediam filmes de longa-metragem. O controle nazista da mídia foi de tal dimensão, que, após a derrota de Hitler, em 1945 (na Alemanha se fala em libertação em vez de derrota), quando o país foi ocupado pelas Forças Aliadas (Estados Unidos, França, Inglaterra e Rússia), a mídia alemã foi completamente reestruturada, censurada e democratizada. Essa reforma é parte do processo de "desnazificação" do país nesse período, assim como o Tribunal de Nuremberg. Em Hamburgo, por exemplo, os ingleses produziam ou rigidamente censuravam o conteúdo midiático, pois não confiavam nos alemães após o período do terror nazista.

A propaganda e a repressão nazista intensa, porém, não podem ser vistas isoladas da estratégia geral nazista de mobilização e nazificação da sociedade inteira. Os nazistas queriam liquidar toda e qualquer vida privada e submeter todas as áreas do cotidiano ao seu controle. Para alcançar esse objetivo, o regime nazista ordenou a famigerada Gleichschaltung, uma política agressiva de forçar todas as organizações, tanto oficiais (p. ex. parlamentos municipais) quanto privadas (sindicatos,

\footnotetext{
3 A literatura sobre a propaganda nazista é imensa e não cabe listar-la aqui. Além de Hildebrand (2003, p. 243-245), Wildt (2008, p. 40-51) e Zimmermann (2008) como referências para a introdução no assunto por meio de resumos dos principais debates, sugiro fontes primárias, como a publicação completa de Joseph Goebbels, e o capítulo sobre propaganda no notório livro de Hitler Mein Kampf, publicado em 1925. Em 2016, o Instituto de História Contemporânea (Institut für Zeitgeschichte), em Munique, publicou uma versão crítica comentada, que oferece notas explicativas elaboradas por especialistas na história do nazismo. O projeto durou sete anos. Essa é a primeira e a mais importante edição crítica da obra panfletária.
}

grupos de interesses, etc.) a submeter-se ao controle nazista (HEHL, 2001, p. 6-8; HILDEBRAND, 2003, p. 1-65). Na maioria dos casos, organizações existentes foram desmanteladas e organizações completamente novas foram criadas (p. ex. os sindicatos foram fechados, e um sindicato nazista criado). Não houve mais vida privada "normal" - instituições ou espaços não infiltrados e controlados pelos nazistas. Os nazistas também criaram novas organizações cuja participação era obrigatória. A ideia era a de que ninguém poderia escapar da ideologia racista. Desde 1936, por exemplo, cada jovem entre dez e dezoito anos foi obrigado por lei a participar da Hitlerjugend, que, em 1939, atingiu 8 milhões de jovens (HEHL, 2001, p. 30-31; HILDEBRAND, 2003, p. 59). Se uma pessoa se recusasse a mandar seu filho para o Hitlerjugend, teria que temer a visita do Geheime Staatspolizei (Gestapo) ou, na pior das hipóteses, o campo de concentração. O nazismo, para resumir, tentou completamente penetrar e controlar a vida cotidiana dos alemães. O espaço para escapar ou até para se opor aos nazistas era muito limitado e até perigoso, como evidenciam as tentativas de resistência, as quais normalmente terminaram em morte (p. ex. Sophie Scholl ou Graf von Stauffenberg). Por outro lado, houve também muitos alemães que voluntariamente apoiaram o nazismo (KERSHAW, 1980).

No Brasil, o primeiro aparato estatal de propaganda e censura sistemática, o Departamento de Imprensa e Propaganda (DIP) (1939-1945), inspirou-se nas propagandas fascistas da Europa (CAPELATO, 1998, p. 281 e 2003, p. 125). Ao contrário da AERP e do ARP, o DIP combinou as duas funções (propaganda e censura) num único órgão. Enquanto é impossível, na extensão do presente artigo, também abordar o conteúdo do DIP em detalhes, podemos destacar aqui algumas características centrais a respeito da sua estratégia de interferir na vida cotidiana do brasileiro comum e de seu alcance. Do ponto de vista institucional, semelhante ao Reichspropagandaamt dos nazistas, o DIP produziu ativamente propaganda, exerceu controle direto na mídia de massa e interferiu diretamente na produção cultural (CAPELATO, 1998, p. 42, 69-70; LENHARO, 1986). Utilizando a imprensa como veículo principal, o DIP controlou o conteúdo transmitido (60\% do material publicado era preparado diretamente pela Agência Nacional) e obrigou os jornalistas a se licenciar para poder trabalhar, de forma semelhante aos nazistas, que também forçaram todos os jornalistas a se registrar na chamada Reichskulturkammer (CAPELATO, 1998, p. 67-70, 74-75; HILDEBRAND, 2003, p. 245). 
Diferentemente dos nazistas, o DIP não utilizou o rádio de uma maneira tão intensa, e as responsabilidades eram mais fragmentadas, enquanto na Alemanha de Hitler, de modo geral, eram mais centralizadas (CAPELATO, 1998, p. 78). O DIP foi o órgão pioneiro de intervenção estatal direta na cultura, com o objetivo de gerar a "unidade nacional", mesclando assim "cultura, política e propaganda" em uma única estrutura (CAPELATO, 2003, p. 125).

A política do Estado Novo como um todo, e a propaganda do DIP em específico, visavam a infiltrar a vida privada do brasileiro (CAPELATO, 1998, p. 243). A historiadora e especialista em propaganda varguista, Maria H. Capelato (2003, p. 113), enfatiza como elemento fundamental a nova relação entre o público e o privado (em geral, uma nova relação entre o Estado e a população). Ao mesmo tempo em que houve um empoderamento simbólico e social, também se praticou o seu oposto; ameaçou-se a liberdade e institucionalizouse a repressão política. Esse aspecto também foi trabalhado por Ângela C. Gomes na sua obra clássica sobre a legislação trabalhista, interpretada, por um lado, como concessão histórica de direitos trabalhistas e, por outro lado, como meio de controle e repressão do trabalhador pelo Estado. Como bem formulou Castro, com essa política de aproximação entre o Estado e a vida privada, o Estado Novo criou uma "cidadania de trabalho" (CASTRO, 1988; CAPELATO, 2003, p. 122). Após os anos 1930, surge a ideia do pacto político entre o Estado e o povo (povo compreendido como trabalhador urbano), e a propaganda estadonovense promove um modelo político-social-cultural de caráter autoritário e corporativo (CASTRO, 2013, p. 30). Essa nova cultura política de cidadania virou ferramenta de destaque para a legitimação do poder, e foi promovida pelo DIP em várias publicações e campanhas, a fim de influenciar o cidadão brasileiro no sentido de se identificar com o ditador Vargas (CAPELATO, 2003, p. 140).

\section{A propaganda e o cotidiano no regime militar}

Independentemente de o regime militar (19641985), assim como o Estado Novo, ter carecido de legitimidade eleitoral, os generais da ditadura militar brasileira pretendiam passar uma imagem de um regime democrático e se distanciar da Era Vargas. Isso explica por que, no início, o regime militar rejeitou a instalação de um órgão de propaganda oficial semelhante às grandes máquinas de propaganda, como o Reichspropagandaamt dos nazistas ou o DIP. Em geral, a propaganda da época militar pode ser dividida em três fases: a propaganda privada pré e pós-golpe (1962-1968), a propaganda oficial a partir de 1968, institucionalizada na Assessoria Especial de Relações Públicas (AERP) e na Assessoria de Relações Públicas (ARP), e, finalmente, a propaganda pós-1979 da Secretaria Especial de Comunicação (SECOM), um órgão muito maior e mais profissionalizado. A última é a propaganda menos pesquisada das três fases. Os principais órgãos ativos nas campanhas contra Goulart foram o Instituto Brasileiro de Ação Democrática (IBAD, fundado em 1959) e o Instituto de Pesquisas e Estudos Sociais (IPÊS, criado em 1962 e fechado, em todas as sedes, em 1971). Ambos órgãos de propaganda são bem pesquisados (DREIFUSS, 1981; GARCIA, 1990; ASSIS, 2001; FICO, 1997). É importante frisar que nem o IBAD nem o IPÊS foram instituições oficiais. Ambas foram entidades privadas, financiadas comprovadamente por empresas nacionais e internacionais, e, como alguns pesquisadores têm argumentado, também pela Agência Central de Inteligência (Central Intelligence Agency, CIA) (DREIFUSS, 198, p. 229, 337-338; LEACOCK, 1979, p. 640, 669).

Um órgão oficial de propaganda só surgiu no final dos anos sessenta, quando uma pesquisa do Instituto Brasileiro de Opinião Pública e Estatística (IBOPE) revelou que, naquele momento, a popularidade do regime estava em baixa. Por isso, em 1967, o então presidente, General Costa e Silva, formou um pequeno grupo de relações públicas, chefiado pelo Coronel Hernani d'Aguiar, com o objetivo de melhorar a popularidade da presidência e do regime (BIBLIOTECA NACIONAL/AERP, 1 은 Seminário, 1967, p. 41-42). Mais tarde, no dia 15 de janeiro de 1968 , uma instituição própria foi instalada para coordenar as relações públicas do regime de uma maneira mais sistemática, a Assessoria Especial de Relações Públicas (AERP). A AERP atuou até março de 1974, e, após dois anos sem a existência de um órgão específico para a propaganda oficial, foi criado, em 1976, um órgão muito semelhante, a chamada Assessoria de Relações Públicas (ARP). A ARP surgiu para preparar as eleições de 1976, já que, em 1974, o partido do regime militar tinha sofrido uma derrota terrível nas urnas. Essa segunda fase de propaganda (da AERP e da ARP) foi estudada na obra clássica de Carlos Fico (1997). Também foi objeto de estudo de Nelson Jahr Garcia (1990), cujo livro - apesar da interpretação marxista 
que reduz a análise da propaganda à perspectiva de luta de classes, negligenciando outras explicações - oferece informações empíricas, ricas e detalhadas, sobre essa fase da propaganda. ${ }^{4}$

Ao contrário das grandes máquinas de propaganda associadas às políticas ditatoriais do início do século $\mathrm{XX}$, a AERP foi deliberadamente pequena. O seu chefe, Coronel Otávio Costa, preferiu manter uma aparência democrática no seu desenho institucional e reduziu os recursos financeiros e pessoais a um mínimo. Profissionais do mercado privado foram contratados para a elaboração de filmes (SCHNEIDER, 2014, p. 16-17). Tanto Costa quanto o chefe da instituição sucessora ARP, José Camargo Toledo, refutaram qualquer semelhança entre a AERP/ARP e o DIP (FICO, 1997; SCHNEIDER, 2014) ${ }^{5}$. Enquanto o DIP, o grande órgão de propaganda do Estado Novo, foi um órgão enorme com muitos funcionários, que também produzia propaganda, a AERP tinha somente uma equipe composta por seis funcionários principais e o setor administrativo - 50 pessoas no total (CAM, AERPa, [1969?]). A Agência Nacional, um outro órgão de notícias oficias, que sucedeu o DIP e já existia antes do golpe de 1964, tinha nove vezes mais empregados na época.

Outra diferença estratégica era a contratação (hoje diria-se terceirização) da produção de filmes, pois nem a AERP nem a ARP elaboravam as campanhas, mas sim ambas contratavam profissionais cinematográficos (CAM, AERPa, [1969?], item 7.1. e apêndice modelo 14). Isso possibilitou o menor tamanho do órgão e fortaleceu a ideia do mercado livre, promovida pelo regime naquela altura da Guerra Fria e marcada pela disputa entre o sistema capitalista e comunista. ${ }^{6} \mathrm{~A}$ aparência "democrática" da propaganda oficial não se refletia somente no seu desenho institucional, conteúdo e funcionamento, mas também na estética das campanhas, assuntos não cobertos neste artigo por falta de espaço (ver FICO, 1997, p. 120-143; SCHNEIDER, 2014, p. 26-64).

Ao contrário da propaganda nazista, que visava a mobilizar os espectadores, as campanhas oficiais

\footnotetext{
4 Além desses livros, há algumas teses de mestrado, p. ex Galletti (1980) e Lima (1998). Para mais literatura sobre temas relacionadas à propaganda do regime, consulte as bibliografias de Fico (1997) e Schneider (2014).

5 Para somente dar dois exemplos: 'Otávio Costa diz que AERP não pretende ser o antigo DIP nem mudar opiniões', Jornal do Brasil, 24 de abril de 1970, p. 3; 'A propaganda sutil que cobre o Pais', O Estado de São Paulo, 3 de augusto de 1976, p. 29.

6 Sobre o procedimento de produção, veja também 'A grande campanha', Veja, 19 de maio de 1976, p. 29.
}

do regime militar brasileiro tinham um caráter desmobilizador e aparentemente apolítico. Fingiam que o Brasil estava vivendo uma época de harmonia, sem conflitos sociais nem preocupações. Como bem elaborou Fico (1997, p. 130-38), o discurso dos filmetes da AERP paradoxalmente recorria a um vocabulário que fingia que os brasileiros podiam participar da vida social e política; slogans como "Você constrói o Brasil" eram comuns. Na realidade, porém, o cidadão brasileiro estava amplamente privado dos seus direitos políticos (direito ao voto, direito à proteção da pessoa, etc.) e até dos seus direitos sociais, considerando que o chamado milagre econômico somente beneficiava algumas camadas da sociedade brasileira, enquanto o abismo social aumentava (DRAIBE, 1994). Também é importante frisar que o regime militar tanto coincidiu com quanto estrategicamente apoiou o investimento na infraestrutura e nas comunicações de massa (SCHNEIDER, 2014, p. 76, p. 115). Essa política, porém, não foi nenhuma especificidade, mas um elemento comum em todas as ditaduras do século $X X$. Enquanto o regime militar brasileiro investiu na infraestrutura da televisão, o regime nazista distribuiu estrategicamente o chamado Volksempfaenger, um rádio moderno subvencionado pelos nazistas para melhor difundir a sua propaganda (ZIMMERMANN, 2007, p. 149).

\section{Meios e alcance da propaganda}

A AERP e a ARP usaram vários meios de propaganda, os quais estão registrados nos seus catálogos de produção anuais: filmes de curta-metragem para a televisão e o cinema (os filmetes), produções para o rádio, e também para públicos diversos, especialmente para as palestras presidenciais (COST, AERP [1969?]). Os meios mais inovadores e importantes foram os filmetes para a televisão e as produções para o rádio (ESCOLA SUPERIOR DE GUERRA, 1970; GARCIA, 1990, p. 78). O rádio atingiu o maior número de brasileiros, embora a televisão estivesse ganhando força (CAM, AERP, [1974?], p. 36; Entrevista Rabaça, 2007). Para definirmos o impacto da propaganda oficial na vida cotidiana dos cidadãos brasileiros, podemos começar por perguntar: quem foi influenciado?

Em 1972, dois terços da população brasileira tiveram acesso à mídia de massa (PINTO, 1973, p. 67). A maioria tinha acesso ao rádio: no censo de 1970, consta que $59 \%$ de todas as casas tinham um rádio, e esse número aumentou para 80\% em 1972 (PINTO, 
1973, p. 65; S. A. 1974, p. 34). Em 1972, pouco mais de um terço das casas brasileiras tinham acesso à televisão, e $60 \%$ das famílias urbanas tinham um aparelho em casa (PINTO, 1973, p. 64-68). Estima-se que, em 1973, entre 42 e $48 \%$ da população urbana assistia à televisão no horário nobre - no chamado prime time (PINTO, 1973, p. 66). No caso do cinema, em 1974, 48\% dos brasileiros com mais de 15 anos frequentavam o cinema regularmente nos centros urbanos (S. A., 1974, p.34). A maioria deles era relativamente jovem, de alta renda e masculina (em 1975, 64\% eram homens) (WICKERHAUSER, 1975, p. 14-16). Isso significa que, enquanto no final dos anos 1960, os curtas-metragens da AERP atingiram predominantemente a classe média e alta, por volta de 1973, a parcela que frequentava o cinema ou possuía uma televisão já era quase a metade da população urbana. Ou seja, metade da população urbana já podia assistir aos filmetes (Entrevista Costa 02/03/2007; PINTO, 1973). Esses dados também mostram que o alcance da mídia de massa, incentivado pelo regime, aumentou com o passar de tempo.

Mesmo sabendo que, em 1973, o alcance da propaganda oficial foi significante (com quase 50\% da população brasileira urbana podendo assistir aos filmetes; PINTO, 1973, p.66), resta compreender como ela foi recebida. Baseados em quais evidências podemos analisar a recepção da propaganda? Como podemos definir o impacto da propaganda oficial na opinião pública sob o regime ilegítimo? Como esclareci no início deste artigo (e pensando como historiadora), esse trabalho só pode ser feito empiricamente, pois qualquer pressuposto teórico seria uma simplificação.

Infelizmente, a reconstrução empírica no caso da ditadura brasileira não é tarefa fácil. A AERP não fazia levantamentos sistemáticos sobre a percepção de suas campanhas pela população brasileira. Embora um documento constituinte da AERP (BN, AERP 1968, p. 3-9, 13) mostre que inicialmente previa-se que a AERP pesquisasse a opinião pública e produzisse resumos diários e semanais junto ao Serviço Nacional de Informação (SNI), isso nunca se concretizou. Em outras ditaduras do século XX, isso foi bem diferente. Para reconstruir a recepção da propaganda nazista, por exemplo, podemos recorrer aos chamados Meldungen aus dem Reich (BOBERACH, 1984), uma coletânea de relatórios mensais escritas por espiões nazistas sobre diversos fatores. Esses relatos também contam como o público reagiu na sala de cinema. Durante a República Democrática Alemã (RDA), houve uma pesquisa sistemática pelo serviço de informação, o
Staatssicherheitsdienst (Stasi) sobre a recepção dos filmes na televisão. Essas são fontes preciosas para se estudar a questão da recepção da propaganda.

No caso da AERP e da ARP, carecemos desse tipo de fontes. Ao contrário do previsto, o SNI acabou escrevendo relatórios de "opinião pública" (basicamente resumos de artigos críticos dos jornais e de manifestações antirregime), e tanto a AERP quanto a ARP se desentendeu profundamente com agentes do SNI (FICO, 1997; SCHNEIDER, 2014). Pesquisas feitas pelo IBOPE sobre a recepção da propaganda aerpiana seriam caras demais, e somente uma pesquisa foi feita em 1973 sobre a campanha Rondon, um projeto para enviar estudantes voluntários à Amazônia para lecionar (CAM, AERP, 1974, p. 45). Segundo o relatório final da AERP (CAM, AERP, 1974, p. 45-46) e entrevistas com os membros da AERP (Entrevista com Costa, 02/03/2007; D'ARAÚJO e CASTRO, 2006, p.43), as campanhas foram avaliadas das seguintes duas maneiras: primeiro, os filmes foram pré-lançados para estudantes de comunicação da Universidade Federal de Brasília (UnB) e para amigos e oficiais dentro do Planalto para obter feedback. Segundo, a AERP analisou atentamente quaisquer comentários após a estreia dos filmetes, tanto de militares e membros da câmara quanto da imprensa. Por essa limitação de fontes, nos casos da AERP e da ARP, temos que fazer um trabalho de "detetive", tentando identificar pequenas pistas para traçar uma análise.

Artigos na imprensa, entrevistas de história oral com os membros aerpianos e o relatório final da AERP (CAM, AERP 1974) sugerem que, de modo geral, os filmetes foram bem recebidos. Por exemplo, uma série de artigos na imprensa revela o sucesso de campanhas específicas, como a da figura de Sujismundo, um desenho animado. ${ }^{7}$ Sujismundo foi tão famoso que, numa votação escolar, uma turma o elegeu como o seu herói predileto, antes mesmo de Zorro e Batman. Em 1971, a revista semanal Visão escreveu que a AERP recebia alguns milhares de cartas dos leitores, após lançar uma campanha encorajando a população a ler livros. Infelizmente, parece que tais cartas não foram preservadas (não podem ser localizadas nem no Arquivo Nacional nem na Biblioteca do Planalto). Segundo o relatório final da AERP (CAM, AERP 1974,

\footnotetext{
“'Prevenildo', o irmão de 'Sujismundo', vai liderar campanha contra acidente", Jornal do Brasil, 21 de novembro de 1972, p. 14; "Ceará forma turma "Sujismundo",, Jornal do Brasil, 1 de dezembro de 1972, p. 14; "A AERP de volta", Veja n. 382, 31 de dezembro de 1975, p.22; Carlos Monforte, "Como no sabão, a qualidade é tudo", $O$ Estado de São Paulo, 16 de outubro de 1977, p. 8.
} 
31, 36, 53), duas campanhas de 1971 fizeram sucesso: 'É tempo de construir' e 'Ontem, hoje, sempre Brasil'.

Quanto ao seu estilo de propaganda esteticamente inovador, há vários indícios de que a estética aerpiana foi elogiada, premiada e mesmo imitada. A AERP foi elogiada em 1970 pela revista Veja (n. 81, 25 de março de 1970, p. 84). O maior jornal de propaganda e marketing da época, Propaganda, celebrou o fato de que a AERP popularizou o desenho animado (por meio do personagem Sujismundo), um gênero que havia sido recusado anteriormente. Segundo o relatório final da AERP (CAM, AERP 1974, p. 31), as suas campanhas foram imitadas pelos agentes de propaganda comercial. Esse argumento faz sentido, principalmente se considerarmos que a AERP ganhou vários prêmios pelas suas campanhas (SCHNEIDER, 2014, p. 106). Assim sendo, mesmo que as fontes sobre a recepção da propaganda aerpiana sejam escassas e sutis, artigos na imprensa, premiações, entrevistas orais e o relatório final da AERP sugerem que, de modo geral, as campanhas foram bem recebidas. Talvez a prova maior disso é o fato de que a propaganda comercial imitou o estilo aerpiano e, respectivamente, para vender produtos ao consumidor, a propaganda comercial é obrigada a responder ao gosto popular.

Já que neste artigo foquei na questão do alcance da propaganda oficial no cotidiano dos brasileiros, gostaria de pelo menos mencionar outro aspecto importante para compreender a propaganda pró-regime no governo militar brasileiro. Além da AERP e ARP, houve outros órgãos oficiais que se envolveram na propaganda e que sabotaram o papel centralizador que, segundo a lei, cabia à AERP/ARP. Também houve propagandistas civis como a grande mídia e a propaganda comercial, atores do mundo privado que muitas vezes produziram - ativa e voluntariamente propaganda chapa-branca para o regime; um tipo de propaganda muito mais óbvio que as campanhas da própria AERP ou ARP. A literatura (e muito mais a memória social) ainda confunde os vários difusores de propaganda, simplificando um quadro de atores de propaganda oficias e privados que de fato é bem mais complexo (SCHNEIDER, 2014, p. 65-84).

\section{O cotidiano brasileiro em comparação}

Para resumir: Qual então foi a influência da propaganda militar na vida cotidiana dos cidadãos brasileiros? E quais as diferenças principais com outras ditaduras do século XX? Se consideramos a propaganda aerpiana em conjunto com outros órgãos de Estado, e no sistema do regime militar brasileiro como um todo, podemos concluir que a propaganda, como uma ferramenta para influenciar a população e justificar o poder do regime ilegal, atingiu a vida cotidiana de muitos brasileiros pelos meios de comunicação em massa. A análise dos dados da mídia mostrou que a maioria dos brasileiros teve acesso ao rádio e, por conseguinte, foi submetida à propaganda oficial. Pelo menos a partir de 1973, 50\% dos cidadãos urbanos tinham acesso à televisão, onde todos os dias antes da novela das oito horas foram exibidos os filmetes aerpianos e arpianos (PINTO, 1973, p. 66). Também não podemos deixar de considerar de que houve outros propagandistas (além da AERP/ARP) não abordados aqui, que influenciaram o cotidiano dos brasileiros. Ademais, além das propagandas, houve vários outros fatores que estimularam o apoio ao regime militar (emprego, benefício profissional, etc.).

Mesmo assim, o grau de influência da propaganda pró-regime na vida cotidiana era muito menor no Brasil do que em outras ditaduras do século XX. Isso se deve em grande parte ao menor tamanho e isolamento da AERP e da ARP no regime ditatorial; tanto voluntário (desenho institucional pequeno e aparentemente democrático) quanto involuntário (conflitos intramilitares, principalmente com o SNI; desrespeito da função centralizadora da AERP pela lei). Em geral, a propaganda oficial do regime (AERP, ARP) e a política frente ao povo brasileiro (a relação Estadocidadão) foi de caráter desmobilizador e até alienador. Diferentemente do nazismo, por exemplo, o cidadão comum não foi obrigado a participar de organizações de presença obrigatória, como o Hitlerjugend, e a ditadura brasileira nunca submeteu organizações estaduais ou privadas totalmente ao seu controle. Houve controle e intimidações em muitas áreas, mas sempre um controle parcial, deixando a vida privada dos brasileiros comuns, daqueles pouco interessados na vida política, basicamente intacta. ${ }^{8}$

O regime militar nunca ansiou a mobilização total das massas. Muito pelo contrário, o regime celebrava a iniciativa privada, característica do sistema capitalista. Não quis parecer ditatorial, refutando qualquer comparação com Vargas ou com os nazistas. A AERP e a ARP produziram filmetes na maioria aparentemente

\footnotetext{
8 Obviamente isso não foi o caso dos milhares de brasileiros na oposição contra o regime cuja vida cotidiana foi invadida de uma maneira brutal. As formas de invasão eram as mais variadas: perda de emprego, vigilância, perseguição, exílio, prisão, tortura, desaparecimento e assassinato.
} 
apolíticos com temas como harmonia, paz e orgulho nacional, ou estimulando os telespectadores a vacinar as suas crianças e a economizar água. Ambas respeitaram empresas privadas (contratando produtoras cinematográficas, fortalecendo assim um lema central do sistema capitalista - o santo mercado livre). Os órgãos oficiais de propaganda nunca visaram a se intrometer, de uma maneira penetrante e explícita, na vida cotidiana daqueles setores da sociedade não envolvidos na oposição política. Já que desejava manter uma aparência democrática, a vida privada intacta, não invadida, foi o modelo escolhido. Mesmo que a repressão do regime (violência, vigilância, censura) tenha sido sistemática, ela não afetou cada cidadão. A repressão atingia - na maioria dos casos grupos específicos (a oposição política, movimentos trabalhistas, indígenas etc.), que, como todos sabemos, sofreram violências brutais.

Embora sempre seja difícil comparar regimes muito diferentes - e o regime nazista tenha um caráter completamente distinto do regime militar-, discordo da análise de Heloiza H. G. de Matos (1989, p. 152) (em outras partes muito rica), de que a comunicação do governo Médici teria afetado "todos os setores do sistema social". Também discordo da análise de Weber (2000, p. 150) que, sem base empírica, argumenta: "O processo comunicativo atravessou todas as instâncias e regulou todas as práticas sociais através das suas dimensões discursivas e simbólicas (...)". Isso sim foi o caso da ditadura nazista, com a mobilização forçada de cada cidadão alemão, e com a política estratégica de colapso das esferas pública e privada. No mundo nazista, o cidadão comum não podia escapar da mobilização política nazista, pois todas as organizações (igreja, associações, imprensa) eram nazificadas, além de terem sido criadas novas organizações cuja participação era obrigatória, como a Hitlerjugend.

\section{Condicionando tipos de consentimento}

Contrastar a influência do regime militar no cotidiano brasileiro com aquela de outras ditaduras do século XX convida-nos a refletir sobre o que condiciona as formas distintas de consentimento: pode-se ponderar, por exemplo, se a mobilização do cidadão brasileiro no seu cotidiano era ou não necessária. Será que o regime militar brasileiro era apoiado ou pelo menos aturado pela maioria dos brasileiros? Por que não foi necessário invadir e controlar a vida privada? Será que o grau de consentimento foi suficiente para manter os generais no poder sem maiores esforços? Muitas entidades privadas e empresas apoiaram ativamente o regime porque se beneficiaram dele. $O$ Globo, por exemplo, fez um acordo de cavalheiros com Castelo Branco, recebeu investimentos estrangeiros maciços (na época, ilegais conforme a legislação vigente) e conseguiu assim monopolizar a mídia brasileira (virar cidadão Kane; KUCINSKI, 1994). A maioria das empresas tanto nacionais quanto internacionais beneficiouse do arrocho salarial, da repressão dos sindicatos e do terror anticomunista da época. Como o relatório final da Comissão Nacional da Verdade (CNV, 2014) mostrou, houve atos de tortura até mesmo na própria sede da Volkswagen do Brasil. Parcelas significativas da população tiraram proveito do chamado milagre econômico (1968-1973). Os setores do cinema, da propaganda comercial e da imprensa viveram uma enorme expansão e um fortalecimento da indústria nacional frente a empresas estrangeiras. Enquanto até os anos 1960, o mercado de propaganda comercial e marketing era dominado pelas grandes empresas estadunidenses, foi na década de 1970 que a propaganda comercial brasileira teve o seu coming out e começou a dominar o mercado doméstico (SCHNEIDER, 2014, p. 80-82). No setor cinematográfico, com a fundação da EMBRAFILME, em 1969, o regime não somente sucessivamente controlou o mercado de filmes, mas também consolidou uma indústria nacional de cinema (JOHNSON e STAM, 1995, p. 43-45). Enfim, mesmo considerando que o regime militar não tenha sido unanimemente apoiado, e muito menos constantemente (o apoio flutuou), será que nem foi necessário conquistar o consentimento da maioria da população??

Enquanto alguns tópicos sobre o regime militar brasileiro têm sido bem estudados (p. ex. a censura, o cotidiano das guerrilhas, a tortura, a memória, os movimentos estudantis), a vida cotidiana do "brasileiro comum", do cidadão não ativamente envolvido na oposição política, continua menos estudada. Além do livro de Fico, que indiretamente aborda a temática (1997), destacam-se as pesquisas sobre o apoio civil em momentos específicos como o golpe (DREIFUSS, 1981; ASSIS, 2001; PRESSOT, 2004; CORDEIRO, 2009),

\footnotetext{
9 Não estou sugerindo que haja uma relação causal geral entre a política de mobilização de uma ditadura e grau de consentimento, no sentido de "uma forte política de mobilização e repressão equivale a muita resistência" (o que, por exemplo, não foi o caso do nazismo, pelo menos após a instalação segura dos nazistas no poder em meados de 1936/1937). Mesmo tendo maciço apoio popular, os nazistas mobilizaram e aterrorizaram a sociedade alemã. Mas faz sentido deixar de "invadir" a esfera privada quando não há perigo de contestação ao poder ditatorial.
} 
a época do milagre e do sesquicentenário (CHIRIO, 2001; ALMEIDA, 2009; CORDEIRO, 2015), e da copa mundial (MAGALHÃES, 2014). Embora alguns estudos abordem o apoio civil (DRAIBE, 1994; NAPOLITANO, 2014, p. 160-71) en passant ou desconstruindo o mito do milagre econômico, ainda carecemos de pesquisas aprofundadas que estudem a vida cotidiana brasileira comum (e não o governo, os jornalistas ou a guerrilha) e que diferenciem a pesquisa, provavelmente, por segmentos sociais, abordando o período inteiro (em vez de um momento específico).

Essa ausência certamente se deve, em parte, à dificuldade de reconstruir, com base em fontes empíricas, o que uma parcela significante de brasileiros pensava sobre o regime, e como isso se desenvolveu com o passar do tempo. O muito citado IBOPE de 1971, por exemplo, com uma taxa de aprovação de $82 \%$ para Médici, nem sempre foi interpretado unanimemente como afirmação direta do regime. O cientista político Youssef Cohen (1979), argumenta que, em 1971, a maioria dos brasileiros não se interessava por política, que seus votos eram instáveis, e que o bom resultado de Médici simplesmente deve ser visto como um desinteresse político total. Segundo Cohen, portanto, o IBOPE é pouco representativo para medir o grau de apoio ao regime militar. Outra explicação para a falta de estudos sobre a vida cotidiana no regime militar pode ser a simples inconveniência de tratar desse assunto polêmico.

Em contrapartida, isso significa que as ditaduras do século XX transformam a vida cotidiana de formas diferentes, deixando mais ou menos liberdade de ação, e também provendo espaços e formas diferentes de consentimento. No caso brasileiro, houve propagandistas privados atuando fortemente a favor do regime como a mídia privada ou a propaganda comercial (pelo menos até meados dos anos 1970). Mesmo considerando que, após 1968, a censura da imprensa tenha sido instaurada, obrigando as redações a fazerem "autocensura" ou a engolir um "gorila" na redação, houve muitos jornais que, voluntariamente, justificaram ou até elogiaram o regime opressor (SMITH, 1997). O Jornal da Tarde ou O Globo foram considerados porta-vozes do regime. Enquanto, durante o nazismo, o sistema de propaganda foi centralizado, no caso brasileiro, o espectro de propaganda é mais complexo: é fundamental diferenciar diversos propagandistas, que muitas vezes não cooperaram. ${ }^{10}$

\footnotetext{
${ }^{10}$ Isso não quer dizer que não havia concorrência entre as instituições nazistas também como a famosa disputa entre Joseph Goebbels e Alfred Rosenberg (HEHL, 2001, p. 28). Mas ainda assim
}

A literatura (e muito mais a memória social) ainda confunde os vários autores da propaganda oficial, simplificando um quadro de propaganda de Estado que de fato é bem mais complexo. Afinal, quem esteve atrás da famosa campanha "Brasil: Ame-o ou Deixe-o"? A Operação Bandeirantes (OBAN), ação militar financiada por empresários paulistas. ${ }^{11}$

\section{Referências}

ADORNO, Theodor; HORKHEIMER, Max. Dialectic of Enlightenment. New York: Herder and Herder, 1972.

ALBRECHT, Gerd. Nationalsozialistische Filmpolitik: Eine soziologische Untersuchung über die Spielfilme des Dritten Reiches. Stuttgart: Ferdinand Enke Verlag, 1969.

ALMEIDA, Adjovanes T. S. de. $O$ regime militar em festa: o sesquicentenário da independência do Brasil (1972). Tese (Doutorado em História Social) - Universidade Federal do Rio de Janeiro, Rio de Janeiro, 2009.

ASSIS, Denise. Propaganda e cinema a serviço do golpe, 19621964. Rio de Janeiro: MAUAD, 2001.

BOBERACH, Heinz. Meldungen aus dem Reich 1938-1945: Die geheimen Lageberichte des Sicherheitsdienstes der SS. Hersching: Pawlak Verlag, 1984. Vol. 1-17.

BENJAMIN, Walter. The work of art in the age of mechanical reproduction. Illuminations. Hannah Arendt (Ed.). New York: Schocken Books, 1969

CAPELATO, Maria Helena. Multidões em cena: propaganda política no Varguismo e no Peronismo. Campinas: Papyrus, 1998.

O que o Estado Novo trouxe de novo. In: FERREIRA, Jorge; DELGADO, Lucília de Almeida Neves (Org.). O Brasil Republicano: o tempo do nacional-estatismo. Do início da década de 1930 ao apogeu do Estado Novo. 9. ed. Rio de Janeiro: Civilização Brasileira, 2003.

CASTRO, Ângela Gomes. A invenção do trabalhismo. Rio de Janeiro: Vértice, 1998

Olhando para Dentro: 1930-1964. Rio de Janeiro: Objetiva, 2013. (História do Brasil Nação, 4).

CHIRIO, Maud. Une nouvelle écriture du destin national: la commemoration de l'independence du Bresil soud la dictature militaire (1964-1985). Tese (Mestrado em História Contemporânea) - Universidade de Paris I, Paris, 2001.

COHEN, Youssef. Popular Support for Authoritarian Governments: Brazil under Médici. Tese (Doutorado) - Departamento de Ciência Politica, Universidade de Michigan, Detroit, 1979.

houve uma centralização muito maior conforme ao chamado Führerprinzip, uma hierarquização de poder estrita culminando em Hitler. No Brasil, pelo contrario, instituições de propaganda usaram filosofias e estratégias opostas, e a AERP foi sabotageado na sua tarefa de centralizar a propaganda oficial (SCHNEIDER, 2014).

${ }^{11}$ A OBAN foi o embrião do sistema repressivo nacional CODIDOI, e parece que essa campanha agressiva foi elaborada por militares da chamada linha dura. A AERP rejeitou essa campanha. 
COMISSÃO NACIONAL DA VERDADE (CNV) Relatório. Brasilia: CNV, 2014.

CORDEIRO, Janaina Martins. Direitas em Movimento: a campanha da mulher pela democracia e a ditadura no Brasil. Rio de Janeiro: FGV, 2009.

A ditadura em tempos de milagre: comemorações, orgulho e consentimento. Rio de Janeiro: FGV, 2015.

D'ARAÚJO, Maria Celina; CASTRO, Celso (Ed.). João Clemente Baena Soares: sem medo da diplomacia. Rio de Janeiro: FGV, 2006.

DEFLEUR, Melvin L.; BALL-ROKEACH, Sandra J. Theories of Mass Communication. Nova York e Londres: Longman, 1989.

DRAIBE, Sônia Miriam. As políticas sociais do regime militar brasileiro: 1964-84. In: SOARES, Gláucio; D’ARAÚJO, Maria Celina (Org.). 21 anos de regime militar: balanços e perspectivas. Rio de Janeiro: FGV, 1994.

DREIFUSS, René A. 1964 - a conquista do estado: ação política, poder e golpe de classe. Rio de Janeiro: Vozes, 1981.

ESPAGNE, Michel. Sur les limites du comparatisme en histoire culturelle. In: Geneses. v. 17, n. 1, p. 112-121, 1994. https://doi. org/10.3406/genes.1994.1266

FEJES, S. Critical Mass Communications Research and Media Effects: The Problem of the disappearing Audience. Media, Culture and Society, n. 6, 1984.

FICO, Carlos. Reinventando o otimismo: ditadura, propaganda e imaginário social no Brasil. Rio de Janeiro: FGV, 1997.

FULBROOK, Mary. Historical Theory. Londres e Nova York: Routledge, 2002.

GALLETTI, Maria Luiza Mendonça. Propaganda e Legitimação do poder. Brasil: 1970/1978. Tese (Mestrado) - Departamento da Comunicação, Universidade de Brasília, Brasília, 1980.

GARCIA, Nelson Jahr. Sadismo, sedução e silêncio: propaganda e controle ideológico no Brasil, 1964-1980. São Paulo: Edições Loyola, 1990.

GUREVITCH, Michael; BENNETT, Tony; CURRAN, James; WOLLACOTT, Janet (Ed.). Culture, Society and the Media. Londres e New York: Routledge, 1992.

HALL, Stuart. Culture, Media, Language: Working Papers in Cultural Studies 1972-1979. Londres e New York: Routledge, 1992.

HEHL, Ulrich von. Nationalsozialistische Herrschaft. Muenchen: Oldenbourg, 2001.

HILDEBRAND, Klaus. Das Dritte Reich. Muenchen: Oldenbourg, 2003.

JOHNSON, Randal; STAM, Robert. Brazilian Cinema. Londres e Toronto: Associated University Presses, 1995.

KAELBLE, Hartmut. Die Debatte über Vergleich und Transfer und was jetzt? H-Soz-u-Kult. Disponível em: http://hsozkult.geschichte. hu-berlin.de/forum/2005-02-002. Acesso em: 08 fev. 2005.

KERSHAW, Ian. Der Hitler-Mythos. Volksmeinung und Propaganda im Dritten Reich. Stuttgart: Klett, 1980.

KRACAUER, Siegfried. From Caligari to Hitler. A Psychological History of the German Film. New York: Princeton University Press, 1947.

KUCINSKI, Bernardo. Roberto Marinho. Index on Censorship, v. 23, n.. 4-5, 1994.
LEACOCK, Ruth. JFK, Business, and Brazil. Hispanic American Historical Review, v. 59, n. 4, 1979.

LENHARO, Alcir. Sacralização da politica. Campinas: Papirus, 1986.

LIMA, Odair de Abreu. A tentação do consenso: o trabalho da AERP e o uso dos meios de comunicação como fontes de legitimação dos governos militares (1964-1974). 1997. 180 f. Dissertação (Mestrado em História Social) - Pontifícia Universidade de Campinas, Campinas, 1998.

MAGALHÃES, Lívia Gonçalves. Com a taça nas mãos: sociedade, copa do mundo e ditadura no Brasil e na Argentina. Rio de Janeiro: Lamparina, 2014.

MATOS, Heloiza. Modos de olhar o discurso autoritário no Brasil (1969-74): O noticiário de primeira página na imprensa e a propaganda governamental na televisão. Dissertação (Mestrado) - ECA, São Paulo, 1989.

NAPOLITANO, Marcos. 1964: Historia do regime militar brasileiro. Rio de Janeiro: Contexto, 2014.

PRESSOT, Aline Alves. As marchas da família com Deus pela liberdade e o golpe de 1964. Dissertação (Mestrado em História) - Universidade Federal do Rio de Janeiro, Rio de Janeiro, 2004.

PINTO, Ivan S. The Brazilian Media Scene. In: Propaganda, n. 203, jun. 1973.

RANDERIA, Shalini; CONRAD, Sebastian. Jenseits des Eurozentrismus. Postkoloniale Perspektiven in den Geschichts- und Kulturwissenschaften. Frankfurt am Main: Fischer, 2002.

REIS, Daniel Aarão. Ditadura militar, esquerdas e sociedade. Rio de Janeiro: Zahar, 2000.

RIDENTI, Marcelo. The Debate over Military (or CivilianMilitary?) Dictatorship in Brazil in Historiographical Context. In: The Bulletin of Latin American Research, v. 35, n. 4 (Special Issue: Dictatorship and Its Legacies in Brazil), 2016.

S.A. [Sem Autor]. The Brazilian communications media. In: Propaganda, n. 214, May 1974.

SCHNEIDER, Nina. Brazilian Propaganda: Legitimizing a Military Regime. Gainesville: University Press of Florida, 2014. https://doi.org/10.5744/florida/9780813049908.001.0001

SIQUEIRA, Ethevaldo. Brasil, 500 anos de comunicações: a eterna busca da liberdade. São Paulo: BCP Telecomunicações/Dezembro Editorial, 2000.

SMITH, Anne-Marie. A Forced Agreement: Press Acquiescence to Censorship in Brazil. Pittsburgh: University of Pittsburgh Press, 1997.

WALKER, Katherine. Frankfurt School of Sociological Thought. Research Starters: Sociology [Online], 2015.

WEBER, Maria Helena. Comunição e espetáculos da política. Porto Alegre: Ed. da UFRGS, 2000.

WERNER, Michael; ZIMMERMANN, Benedicte. De la comparaison à l'histoire croisée. Paris: Seuil, 2004.

WICKERHAUSER, Hilda. O cinema como veículo publicitário. In: Propaganda, n. 230, set. 1975.

WILDT, Michael. Geschichte des Nationalsozialismus. Goettingen: Vandenhoeck \& Ruprecht, 2008.

ZIMMERMANN, Clemens. Medien im Nationalsozialismus: Deutschland, Italien und Spanien in den 1930er und 1940er Jahren. Wien: Böhlau, 2007. 


\section{Manuscritos}

BIBLIOTECA NACIONAL [BN], AERP, Io Seminário de relações públicas do executivo, instruções para o funcionamento da A.E.R.P., 30 de setembro a 5 de outubro de 1968, Guanabara (Rio de Janeiro: AERP, 1968).

ARQUIVO PRIVADO OTÁVIO COSTA [COST], AERP, Catálogo de peças produzidas - out. 69/mar 74 (Rio de Janeiro, [1969?]).

ARQUIVO PRIVADO JOSÉ CAMARGO [CAM], AERPa, Manual de serviço de 1969 a 1974 (Rio de Janeiro: AERP, [1969?]).

ARQUIVO PRIVADO JOSÉ CAMARGO [CAM], AERPb, Documentos fundamentais. Planejamento desenvolvido (Rio de Janeiro: AERP, [1969?]).

ARQUIVO PRIVADO JOSÉ CAMARGO [CAM], AERP, Relatório de comunicação social (governo e opinião publica) (Brasília: AERP, [1974?]).
ESCOLA SUPERIOR DE GUERRA, Costa, Otávio (1970) Presidência da República, Escola-maior das Forças Armadas, Escola Superior de Guerra, "Governo e Comunicação social", C116-123-70.

\section{Jornais}

Veja, Visão, Jornal do Brasil, O Estado de São Paulo, e Propaganda.

\section{Entrevistas}

Entrevista com General Otávio Costa, Rio de Janeiro, 02.03.2007. Entrevista com Professor Alberto Rabaça, Rio de Janeiro, 14.03.2007.

Recebido: 31 de julho de 2016 Aprovado: 12 de setembro de 2016

\section{Autor/Author:}

NINA SCHNEIDER nina.schneider@uni-koeln.de

- Pesquisadora Sênior do Centro de Estudos Sobre o Sul Global (Global South Study Center, GSSC) da Universidade de Colônia, Alemanha e Pesquisadora Associada do Zukunftskolleg, Universidade de Constança, Alemanha. Doutora em História na University of Essex, Grã-Bretanha, e pesquisadora visitante do instituto pela pesquisa de direitos humanos (Institute for the Study of Human Rights, ISHR) na Columbia University em 2012, e na Universidade de Brasília em 2015. Publicações recentes incluem: Brazilian Propaganda: Legitimizing an authoritarian regime (University Press of Florida, 2014) e (com Marcia Esparza) Legacies of State violence and Transitional Justice in Latin America: A Janus-faced Paradigm? (Lexington/Rowman \& Littlefield, 2015).

- Senior Research Fellow at the Global South Study Center (GSSC) at the University of Cologne, and Associate Fellow at the Zukunftskolleg, University of Konstanz. PhD in History from the University of Essex, UK, and Visiting Scholar at the Institute for the Study of Human Rights (ISHR) at Columbia University in 2012 and the National Universidade de Brasília (UnB) in 2015. Publications include Brazilian Propaganda: Legitimizing an authoritarian regime (University Press of Florida, 2014) e (com Marcia Esparza) Legacies of State Violence and Transitional Justice in Latin America: A Janus-faced Paradigm? (Lexington/Rowman \& Littlefield, 2015). 